\title{
Evaluación del crecimiento y compatibilidad de hongos de la podredumbre blanca
}

\author{
Evaluation of Growth and Compatibility of white Rot Fungi
}

\author{
J. A. Rojas Barreto ${ }^{\mathrm{a}, *}$
}

A. Hormaza Anaguano ${ }^{a}$

Recepción: 12-feb-14

Aceptación: 21-dic-14

\begin{abstract}
Resumen
El uso de hongos de la podredumbre blanca (HPB) ha generado un gran interés debido a su potencial enzimático, permitiendo a estos organismos degradar una amplia gama de compuestos xenobióticos. Los consorcios fúngicos pueden mejorar dichos procesos de degradación con respecto a los monocultivos y para su asociación debe establecerse previamente su compatibilidad. En este trabajo se evaluó la influencia de dos condiciones nutricionales sobre el crecimiento y la compatibilidad entre tres especies de los HPB, Trametes versicolor, Pleurotus ostreatus y Pleurotus pulmonarius, para su futura utilización como consorcios en el tratamiento de contaminantes orgánicos. Discos de dos especies de los hongos evaluados crecieron por siete días sobre los medios de cultivo agar papa dextrosa (PDA) y agar salvado de trigo (AST). Se evaluaron tres tratamientos, T1: T. versicolor vs $P$. ostreatus, T2: $T$. versicolor vs $P$. pulmonarius y T3: $P$. ostreatus vs $P$. pulmonarius con sus respectivos controles (crecimiento libre). El porcentaje de inhibición micelial obtenido $(<70 \%)$ mostró compatibilidad entre los hongos evaluados en los distintos tratamientos bajo las condiciones nutricionales utilizadas. Con respecto a la tasa de crecimiento, se observó que el medio AST favoreció un rápido desarrollo para los tres hongos en comparación con PDA.
\end{abstract}

Palabras clave: Compatibilidad, Consorcios microbianos, Interacciones, Tasa de crecimiento, Medios de cultivo.

\begin{abstract}
The use of white rot fungi (WRF) has generated a great interest due to its enzymatic potential, allowing these organisms to degrade a wide range of xenobiotic compounds. The fungal consortia can improve these degradation processes with regard to monoculture and for its association, the compatibility should be established beforehand. In this study was evaluated the influence of two nutritional conditions on growth and compatibility between three species of WRF, Trametes versicolor, Pleurotus ostreatus and Pleurotus pulmonarius, for future use as consortia in the treatment of organic contaminants. Two discs of the tested fungal species grew for seven days over the culture medium, potato dextrose agar (PDA) and wheat bran agar (WBA). Three treatments were evaluated, T1: T. versicolor vs P. ostreatus, T2: T. versicolor vs
\end{abstract}

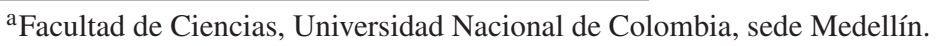

*Autor de correspondencia: juarojasba@unal.edu.co 
P. pulmonarius and T3: P. ostreatus vs P. pulmonarius with their respective controls (free growth). The obtained percentage of mycelial inhibition $(<70 \%)$ showed compatibility between the evaluated fungi in the different treatments under the used nutritional conditions. Regarding to growth rate, it was observed that WBA medium favored a rapid growth for the three fungi compared with PDA.

Key words: Compatibility, Microbial Consortia, Interactions, Growth Rate, Culture Medium.

\section{Introducción}

Los hongos de la podredumbre blanca, HPB, se han venido utilizando en la degradación de compuestos recalcitrantes y xenobióticos por su producción de enzimas, las cuales están asociadas primordialmente con la mineralización de la lignina por rutas inespecíficas [1]. A dichas enzimas se les atribuye la capacidad de oxidar tanto los anillos aromáticos como algunos de los sustituyentes presentes en las unidades de este polímero [1]. Contaminantes orgánicos, tales como los colorantes, plaguicidas e hidrocarburos poliaromáticos presentan una similitud estructural con las unidades de fenilpropano de la lignina, por tanto se estima que su biodegradación ocurre a través de un mecanismo similar al experimentado por la lignina $[1,2,3,4]$.

En los procesos de biodegradación de sustancias recalcitrantes como los colorantes sintéticos, múltiples cepas han sido evaluadas bajo distintas condiciones nutricionales, dando lugar en ciertos casos a bajos porcentajes de decoloración, debido probablemente a la complejidad estructural de estos contaminantes [5]. No obstante, se ha reportado que las asociaciones de dos o más especies de microorganismos, combinaciones conocidas como consorcios microbianos, pueden llevar a cabo procesos de degradación de mayor eficiencia [6,7]. Lo anterior, se explica debido a que los microorganismos cuando están expuestos a limitaciones nutricionales u otros factores de estrés ambiental, estimulan de una u otra forma interacciones benéficas de subsistencia, resultado de su asociación con otros organismos [8]. Así por ejemplo, se ha establecido que la variación en la suplementación de nutrientes del medio de cultivo influye de forma contundente sobre el crecimiento de las especies fúngicas individuales como sobre su posible sinergismo $[6,9]$.

Elementos tales como carbono, nitrógeno, azufre, hierro y otros minerales son indispensables para el crecimiento y producción enzimática de los hongos, donde el carbono es el nutriente de mayor importancia [10]. Como fuente de carbono para dicho crecimiento se han utilizado diferentes carbohidratos como la glucosa, fructosa y almidón, entre otros, en tanto que compuestos como el cloruro de amonio, peptona y extracto de malta han sido empleados como aporte nutricional para el nitrógeno $[11,12]$. Por otro lado, una determinada especie fúngica puede presentar una adaptación distinta a ciertas condiciones nutricionales, incidiendo de forma directa sobre su desarrollo [11,12].

Para el estudio de esas adaptaciones se ha propuesto un sistema de clasificación conocido como la teoría r y K, la cual se basa en las propiedades de crecimiento del microorganismo. Esta teoría sostiene que los organismos adoptan diferentes estrategias para alcanzar la colonización de un ambiente determinado [13]. Así, en un medio limitante de nutrientes, los organismos que adoptan la estrategia tipo $r$ ocupan un espacio tan rápido como les sea posible, por lo cual mantienen altas tasas de reproducción, mientras que los organismos que adoptan la estrategia tipo $\mathrm{K}$ poseen, metabolismos lentos y tasas de reproducción bajas, presentando una colonización más lenta [13].

El establecimiento de consorcios microbianos está determinado tanto por las condiciones nutricionales, generalmente limitadas, como por la compatibilidad, la cual influye en la proporción de las especies que participan en el consorcio [14]. Dado que un consorcio de HPB puede jugar un papel importante en la biodegradación de compuestos recalcitrantes, al potenciar la actividad enzimática por efecto sinérgico entre las especies participantes, la evaluación preliminar de su compatibilidad constituye un requisito previo para una posible asociación exitosa entre las especies [15]. Al respecto, es importante señalar que se han realizado algunos estudios de compatibilidad con asociaciones fúngicas para el tratamiento de colorantes y compostaje de residuos agroindustriales; no obstante, se han limitado a resultados cualitativos de interacciones [14,16]. 
Cabe señalar que se han realizado algunos estudios con consorcios bacterianos, encontrando mayor eficiencia en la degradación de colorantes en un menor tiempo [7]. También, se reporta la utilización de hongos no ligninolíticos, en particular, Aspergillus sp, Penicillium sp, Mucor sp y Fusarium sp, encontrando que su asociación fue más eficiente que las especies individuales en la decoloración de efluentes industriales [17]. De igual forma, los consorcios con hongos lignocelulósicos [16] y entre hongos ligninolíticos [6] han logrado durante la colonización un mejor aprovechamiento del sustrato y así un rendimiento eficiente en la producción de enzimas. Sus interacciones sinérgicas también han mostrado el aumento de la resistencia a la proliferación de otros microorganismos no deseados en el proceso, e igualmente una relación que señala la baja producción de biomasa con un notable incremento en la producción enzimática. Finalmente, es valioso resaltar que los estudios de consorcios con HPB son limitados.

Con el propósito de determinar posibles consorcios fúngicos y potenciar la actividad enzimática para futuros estudios de biodegradación de sustancias xenobióticas, en la presente investigación se evaluaron las interacciones entre tres especies de los HPB. Para ello, se utilizaron dos condiciones nutricionales, agar papa dextrosa (PDA) y agar salvado de trigo (AST), con el fin de determinar de forma cuantitativa su efecto en la tasa de crecimiento y en su compatibilidad intraespecífica, como criterios apropiados para el establecimiento de dichos consorcios.

\section{Materiales y métodos}

\subsection{Cepas}

Se evaluaron tres cepas de los HPB, Pleurotus ostreatus, Pleutorus pulmonarius y Trametes versicolor, obtenidos del cepario del Laboratorio de Tejidos Vegetales de la Universidad de Antioquia, los cuales se reactivaron en agar PDA; los hongos se incubaron a $28{ }^{\circ} \mathrm{C}$ por ocho días. De este medio se tomaron discos ( $0.5 \mathrm{~cm}$ de diámetro) del borde de crecimiento del hongo, los cuales fueron utilizados como inóculo tanto para el estudio del crecimiento libre de las especies fúngicas como de sus posteriores interacciones.

\subsection{Interacción hongo-hongo o enfrentamiento dual}

La evaluación de la compatibilidad de las especies fúngicas se realizó con base en la prueba de inhibición micelial, cuyo protocolo se encuentra previamente descrito [18]. Se evaluaron tres tratamientos (T), de tal forma que se logrará una combinación dual de hongos tanto de la misma especie como de especies diferentes. Así, los ensayos establecidos fueron T1: $T$. versicolor vs $P$. ostreatus, T2: $T$. versicolor vs $P$. pulmonarius y T3: $P$. ostreatus vs $P$. pulmonarius. Las interacciones entre los hongos seleccionados se determinaron utilizando los medios agar PDA OXOID $(\mathrm{pH}=5,5)$ y agar salvado de trigo $(\mathrm{pH}=4,5)$. La composición de este último fue salvado de trigo $175 \mathrm{~g} / \mathrm{L}$, peptona $5,0 \mathrm{~g} / \mathrm{L}$, glucosa 10 $\mathrm{g} / \mathrm{L}$, extracto de levadura $2,0 \mathrm{~g} / \mathrm{L}$, dihidrógeno fosfato de potasio $\left(\mathrm{KH}_{2} \mathrm{PO}_{4}\right) 0,1 \mathrm{~g} / \mathrm{L}$, sulfato de magnesio heptahidratado $\left(\mathrm{MgSO}_{4} \cdot 7 \mathrm{H}_{2} \mathrm{O}\right) 0,05 \mathrm{~g} / \mathrm{L}$, sulfato de manganeso monohidratado $\left(\mathrm{MnSO}_{4} \cdot \mathrm{H}_{2} \mathrm{O}\right)$ 0,076 $\mathrm{g} / \mathrm{L}$ y agar-agar $18 \mathrm{~g} / \mathrm{L}$. Para los ensayos se tomaron cajas de Petri (9 cm de diámetro) con discos de diferentes cepas de hongos aislados, colocados a $4 \mathrm{~cm}$ de distancia el uno del otro, (crecimiento micelial influenciado).

Como control se utilizó el crecimiento libre de cada uno de los hongos de interés, colocando un disco colonizado en el centro de la caja a una distancia de $4,5 \mathrm{~cm}$ del borde (crecimiento micelial libre), el cual fue registrado de forma diaria. Adicionalmente, se monitoreó sobre dichos controles algunas características cualitativas, tales como la densidad del micelio y su textura; criterios que serán utilizados para la selección del mejor medio de crecimiento, dando prioridad a un rápido crecimiento del hongo y a una mayor densidad micelial.

Las cajas de Petri, tanto de los tratamientos como de los controles, se incubaron a una temperatura de $28{ }^{\circ} \mathrm{C}$ durante diez días. Dado que ésta investigación constituye un estudio preliminar para el establecimiento de consorcios fúngicos, los experimentos se realizaron por triplicado para garantizar confiabilidad en los resultados obtenidos.

El porcentaje de inhibición micelial (\%IM) se determinó utilizando la siguiente ecuación (1) [18]:

$$
\% I M=\frac{C M L-C M I}{C M L} * 100
$$


Dónde:

$C M L=$ Crecimiento micelial libre $(\mathrm{cm})$

$C M I=$ Crecimiento micelial influenciado $(\mathrm{cm})$

$\% I M=$ Porcentaje de inhibición micelial

\subsection{Tasa de crecimiento (Tc) de especies fúngicas individuales y de sus consorcios}

También se calculó la tasa de crecimiento por día ( $\mathrm{cm} /$ día) de acuerdo al procedimiento establecido por Benítez y colaboradores [19] mediante la ecuación (2). Para ello, se tomaron los radios de crecimiento micelial de la colonia fúngica del día inicial y final del período evaluado.

$$
T c=\frac{C f-C i}{T f-T i}
$$

Dónde:

$C f$ : Crecimiento diametral final expresado en $\mathrm{cm}$

$C i$ : Crecimiento diametral inicial (día uno) expresado en $\mathrm{cm}$

$T f$ : Tiempo final en el que termina el crecimiento fúngico (día final)

$T i$ : Tiempo inicial (día uno)

\subsection{Análisis estadístico del crecimiento libre de los hongos}

Para evaluar el crecimiento libre de las especies fúngicas se realizó un diseño factorial multinivel $3 \times 2$, donde se seleccionaron tres especies de HPB, Trametes versicolor, Pleurotus ostreatus y Pleurotus pulmonarius, y dos medios de cultivo, PDA y AST. El análisis de varianza (ANOVA) se realizó con el software Statgraphics Centurion XV.II Versión 15.2.06, de uso libre, para establecer la relación entre los factores y la variable de respuesta mediante las diferencias significativas entre los parámetros analizados para los distintos tratamientos. Se tomó como criterio de confiabilidad un porcentaje del 95,0\%. Si el valor $\mathrm{p}$ es menor que $0,05(\mathrm{P}<0,05)$, el factor se considera estadísticamente significativo. La variable de respuesta establecida fue el diámetro de crecimiento fúngico en centímetros.

\section{Resultados y discusión}

\subsection{Crecimiento de los HPB}

De acuerdo a los análisis cualitativos del desarrollo micelial libre y a la cuantificación del crecimiento de los hongos, se encontró de forma general una notable diferencia entre los dos medios utilizados, AST y PDA. En AST se observó la formación de micelio muy denso y algodonoso para los tres hongos y un crecimiento individual rápido, alcanzando la colonización total de todo el medio para las tres cepas a los siete días de evaluación, el cual puede observarse en la figura 1. En PDA, se apreciaron micelios adheridos al medio de cultivo de baja densidad y un crecimiento individual lento, alcanzando la colonización total de todo el medio a los diez días por $P$. ostreatus y $P$. pulmonarius, en tanto que T. versicolor alcanzó dicha colonización total del medio en siete días (figura 1).

El análisis estadístico de la influencia de los medios de cultivo seleccionados sobre el crecimiento de las tres especies fúngicas se presenta en la tabla 1. Dado que la variable de respuesta es un diámetro creciente que alcanzará un valor fijo, no es la medición más apropiada ya que su valor reciente sería muy disperso con respecto al valor inicial. Por lo tanto, se consideró apropiado definir la variable de respuesta como la diferencia entre los diámetros medidos diariamente en centímetros, lo cual permite una mayor homogeneidad en los resultados obtenidos.

Tabla 1. Diferencia de los diámetros del crecimiento libre de los HPB en PDA y AST.

\begin{tabular}{ccccccc}
\hline Día & \multicolumn{2}{c}{ T. versicolor } & \multicolumn{2}{c}{ P. ostreatus } & \multicolumn{2}{c}{ P. pulmonarius } \\
\cline { 2 - 7 } & PDA & AST & PDA & AST & PDA & AST \\
\hline 1 & 1,7 & 1,2 & 0,5 & 1,0 & 1,1 & 0,9 \\
2 & 1,3 & 1,3 & 0,8 & 0,8 & 0,5 & 1,2 \\
3 & 1,6 & 1,8 & 1,5 & 1,4 & 1,4 & 1,5 \\
4 & 1,6 & 1,4 & 1,3 & 1,4 & 0,6 & 1,3 \\
5 & 1,9 & 0,9 & 0,7 & 1,4 & 0,7 & 1,4 \\
6 & 0,6 & 1,4 & 0,9 & 1,5 & 1,2 & 1,8 \\
7 & 0,0 & 0,5 & 1,2 & 1,0 & 1,0 & 0,5 \\
8 & 0,0 & 0,0 & 1,1 & 0,0 & 1,2 & 0,0 \\
9 & 0,0 & 0,0 & 0,7 & 0,0 & 1,0 & 0,0 \\
*P & 0,0006 & 0,0004 & 0,0004 \\
\hline *Significancia (P <0,05) ANOVA.
\end{tabular}

De acuerdo a la tabla 1, es claro que los medio de cultivo utilizados tiene un efecto significativo en el crecimiento del diámetro de las tres especies fúngicas evaluadas, dado las diferencias estadísticas encontradas con respecto al criterio del análisis ANOVA.

\subsection{Tasa de crecimiento (Tc) de las cepas individuales}

Los resultados de la Tc de las cepas individuales evaluadas en el medio AST mostraron un 


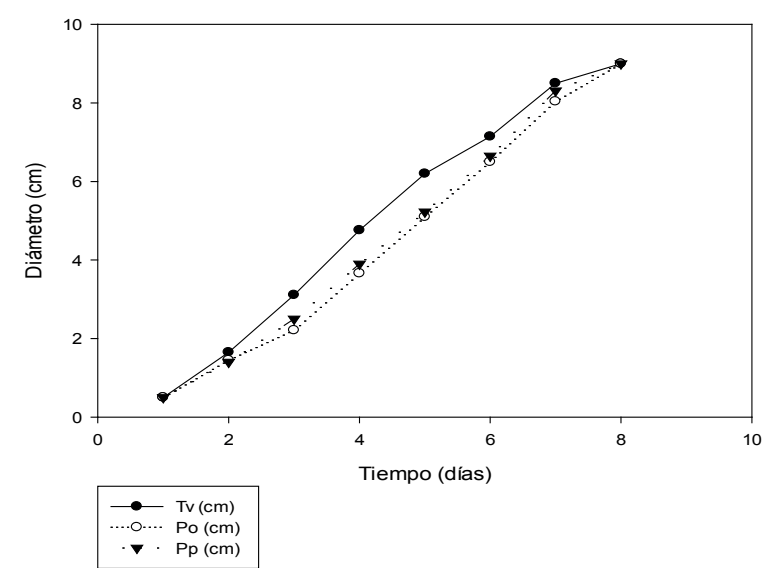

A.

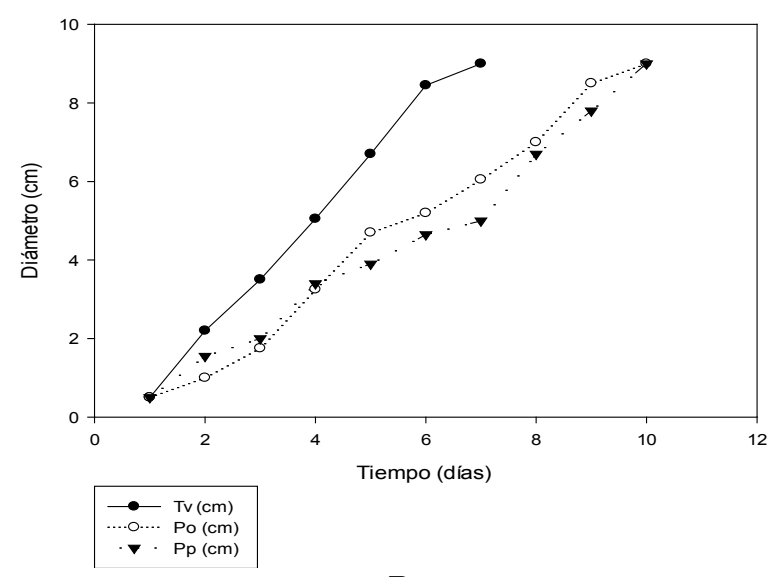

B.

Figura 1. Crecimiento libre para los HPB: A. Medio AST y B. Medio PDA.

desarrollo de 1,21 cm/día para las tres especies. En PDA se obtuvo un crecimiento menor, del orden de $0,94 \mathrm{~cm} /$ día para $P$. ostreatus y $P$. pulmonarius, mientras que $T$. versicolor, registró en este medio un valor de $1,42 \mathrm{~cm} /$ día, superior al encontrado en AST (tabla 2). Este comportamiento puede ser explicado con base en las estrategias $\mathrm{r}$ y $\mathrm{K}$ de colonización de los microorganismos en un ambiente particular. Al parecer T. versicolor adoptó una estrategia $\mathrm{r}$ en la que se emplea gran parte de su energía metabólica en la reproducción para lograr ocupar el medio tan rápido como sea posible, independientemente del alto contenido de nutrientes. Los hongos que siguen este comportamiento se caracterizan por una fácil adaptación frente a la tensión ambiental y a la baja disponibilidad de nutrientes [13].

Tabla 2. Tasa de crecimiento de los HPB individuales en los medios PDA y AST.

\begin{tabular}{ccc}
\hline Hongos & \multicolumn{2}{c}{ Tasa de crecimiento (cm/día) } \\
\cline { 2 - 3 } & Medio PDA & Medio AST \\
$T_{v}$ & 1,42 & 1,21 \\
$P_{o}$ & 0,94 & 1,21 \\
$P_{p}$ & 0,94 & 1,21 \\
\hline
\end{tabular}

\subsection{Interacciones}

Se observaron diferentes interacciones entre los hongos evaluados como resultado de las condiciones nutricionales suministradas por los medios PDA y AST.

En el medio AST se alcanzaron\%IM similares, atribuibles al contenido nutricional, que evita o reduce un ambiente de competencia (tabla 3). No obstante, para los tratamientos $\mathrm{T} 1$ y T2, donde se enfrenta- ron dos organismos de distintos géneros, se apreció una mayor competición, particularmente $P$. ostreatus mostró mayor competencia que $P$. pulmonarius frente a $T$. versicolor, tal como se muestra en la tabla 3 y la figura 2. Resultados similares de competencia debido al género y a la especie de los hongos han sido reportados por otros investigadores $[14,15]$.

Tabla 3. Porcentaje de inhibición de los HPB bajo interacción en los medios PDA y AST.

\begin{tabular}{ccccccc}
\hline \multirow{3}{*}{ Hongos } & \multicolumn{3}{c}{ Porcentaje de inhibición (\%) } \\
& \multicolumn{3}{c}{ PDA } & & \multicolumn{3}{c}{ AST } \\
\cline { 2 - 7 } & T1 & T2 & T3 & T1 & T2 & T3 \\
\hline$T_{v}$ & 41 & 47 & & 56 & 48 & \\
$P_{o}$ & 58 & & 52 & 48 & & 54 \\
$P_{p}$ & & 60 & 53 & & 50 & 47 \\
\hline
\end{tabular}

El medio PDA presenta un ambiente más extremo para los hongos, por su bajo contenido de nutrientes, conllevando a una mayor competencia y dando lugar a unos porcentajes de inhibición micelial del orden de 58 y $60 \%$, para las especies del genero Pleurotus sp., respectivamente, en los T1 y T2. Para el T3, se obtuvieron \%IM equilibrados, ya que los hongos enfrentados pertenecen al mismo género. Por lo anterior, en este medio se reprodujo la tendencia de una mayor competición entre dos especies de género distinto, tratamientos T1 y T2 (tabla 3 y figura 2). Resultados análogos han sido reportados en otros estudios, donde se evaluó la competencia por la interacción de hongos de igual género $[14,15]$.

De acuerdo con el criterio establecido en [15], el porcentaje de inhibición debe encontrarse entre el 70 y el $100 \%$, para definir una inhibición positiva entre los organismos participantes. Según lo 

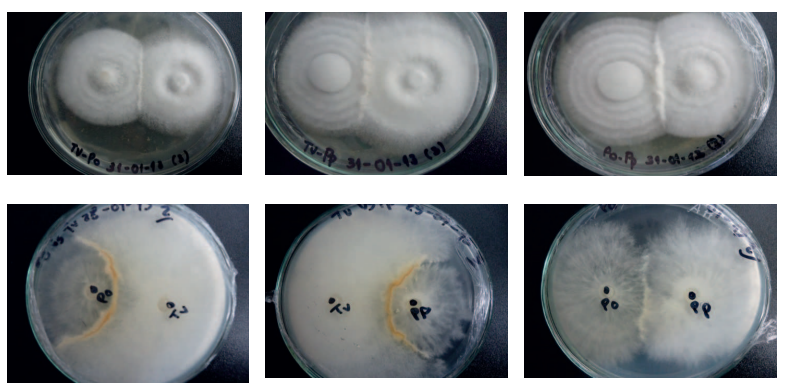

Figura 2. Imágenes parte superior: Interacciones de T1, T2 y T3 en AST. Imágenes parte inferior: interacciones de T1, T2 y T3 en PDA.

anterior y con base en los resultados de la tabla 3, no se encontró en la presente investigación un porcentaje dentro de este rango mencionado. Por tanto, las cepas fúngicas que hicieron parte de los tratamientos evaluados podrían combinarse en consorcios fúngicos y se espera que su asociación conduzca a un incremento en la producción enzimática. $\mathrm{Al}$ respecto, varios estudios han mostrado resultados satisfactorios tanto en la producción de enzimas como en la degradación de xenobióticos utilizando consorcios fúngicos [5,16,17,20-22] Así por ejemplo, los estudios de Yang y colaboradores mostraron un aumentó cinco veces mayor en la producción de la enzima Manganeso peroxidasa por el consorcio de Trametes sp. y Chaetomiun sp. con relación a lo producido por el monocultivo; así mismo, un incremento en el porcentaje de biodegradación de colorantes trifenilmetánicos con un valor del $96 \%$ en comparación al $38 \%$ obtenido por las especies individuales [5].

\subsection{Tasa de crecimiento (Tc) de HPB bajo interacción}

La Tc de las especies fúngicas bajo interacción está relacionada con el comportamiento mostrado por los hongos bajo las condiciones nutricionales de los dos medios de cultivo evaluados. Como observación general y de acuerdo a lo esperado, los tres hongos experimentaron una disminución en la Tc en los dos medios. También se observó que T. versicolor en interacción mostró la mayor Tc en PDA, con un valor promedio de $0,75 \mathrm{~cm} /$ día, como lo registrado para su crecimiento libre en dicho medio (1,42 cm/día).

En el medio PDA, los tratamientos en los cuales se evaluó la interacción de $T$. versicolor frente a $P$. ostreatus y $P$. pulmonarius mostraron una Tc promedio de $0,75 \mathrm{~cm} /$ día para el primer hongo y una Tc de
0,52 cm/día para los dos hongos del género Pleurotus sp. En el T3, los hongos enfrentados P. ostreatus y $P$. pulmonarius exhibieron un crecimiento similar con una Tc de 0,63 y $0,67 \mathrm{~cm} /$ día respectivamente, (tabla 4).

Tabla 4. Tasa de crecimiento de los HPB bajo interacción en los medios PDA y AST.

\begin{tabular}{ccccccc}
\hline \multirow{3}{*}{ Hongos } & \multicolumn{6}{c}{ Tasa de crecimiento (cm/día) } \\
\cline { 2 - 7 } & \multicolumn{5}{c}{ PDA } & TST \\
& T1 & T2 & T3 & T1 & T2 & T3 \\
\hline$T_{v}$ & 0,8 & 0,7 & & 0,59 & 0,7 & \\
$P_{o}$ & 0,52 & & 0,63 & 0,69 & & 0,6 \\
$P_{p}$ & & 0,52 & 0,67 & & 0,63 & 0,72 \\
\hline
\end{tabular}

En el medio AST, el crecimiento de los hongos presentó mayor similitud por el aporte de nutrientes, conllevando a una menor competencia. No obstante, para el tratamiento $\mathrm{T} 1$ se observó que $\mathrm{T}$. versicolor disminuyó su velocidad de crecimiento en comparación con el medio PDA, pasando de 0,80 a 0,59 $\mathrm{cm} /$ día, (tabla 4). Esto se explica de forma análoga a lo argumentado en las Tc de las especies individuales, donde el comportamiento del T. versicolor obedece principalmente a la estrategia $\mathrm{r}$, caracterizada por una alta velocidad de crecimiento en condiciones nutricionales menos favorables [13].

\section{Conclusiones}

Las diferencias marcadas en el crecimiento y las interacciones de los HPB del presente estudio se explican principalmente debido a la distinta composición de los medios evaluados, a la disponibilidad de nutrientes y a las estrategias de adaptación de los mismos. Así por ejemplo, la estrategia-r desempeñó un papel importante en el comportamiento de $\mathrm{T}$. versicolor. En particular, el AST resultó ser el medio más apropiado para el desarrollo de los HPB por su alto aporte nutricional.

En cuanto a las velocidades de crecimiento de los HPB bajo interacción se observó una disminución en los dos medios utilizados, no sólo por el desplazamiento micelial, sino también por el efecto de las condiciones nutricionales.

La evaluación de consorcios microbianos es esencial para el desarrollo de procesos fermentativos mixtos. Los resultados obtenidos en este estudio sobre el porcentaje de inhibición micelial, menores al $70 \%$, señalan que los tres hongos evaluados pueden combinarse en consorcios. 


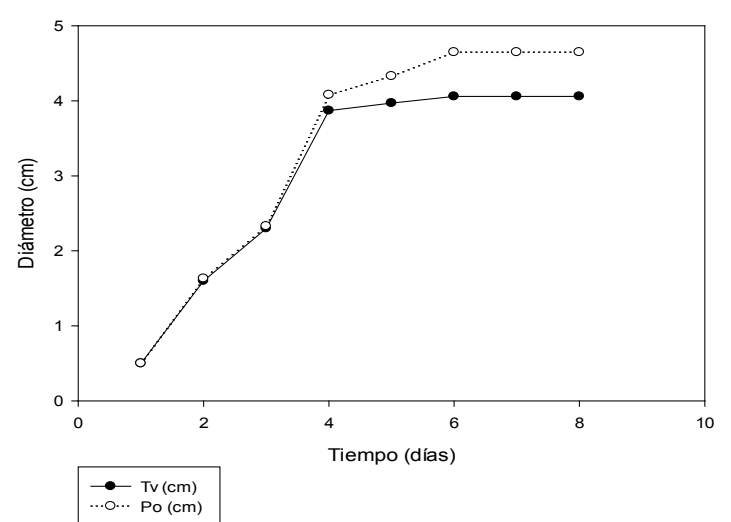

A.

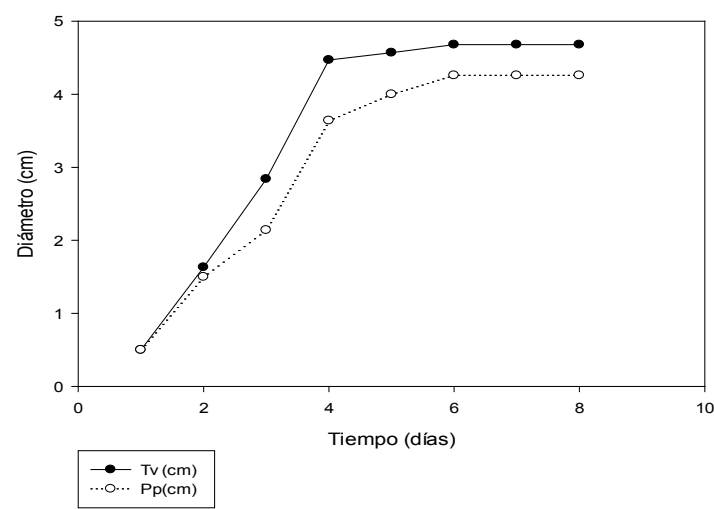

B.

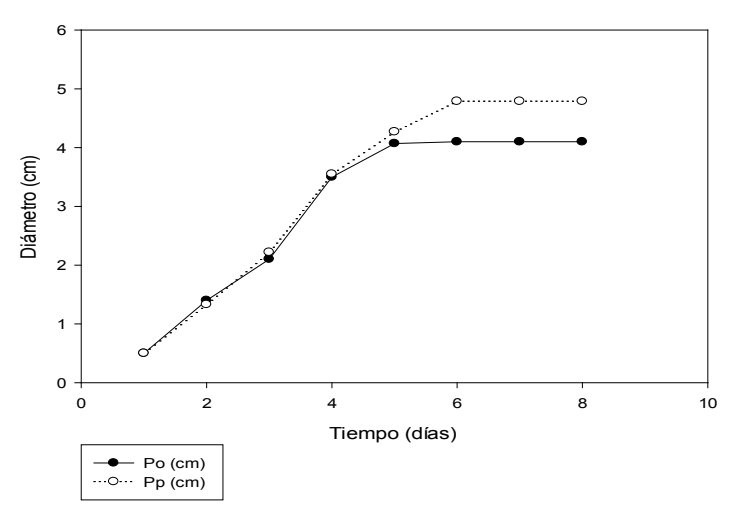

C.

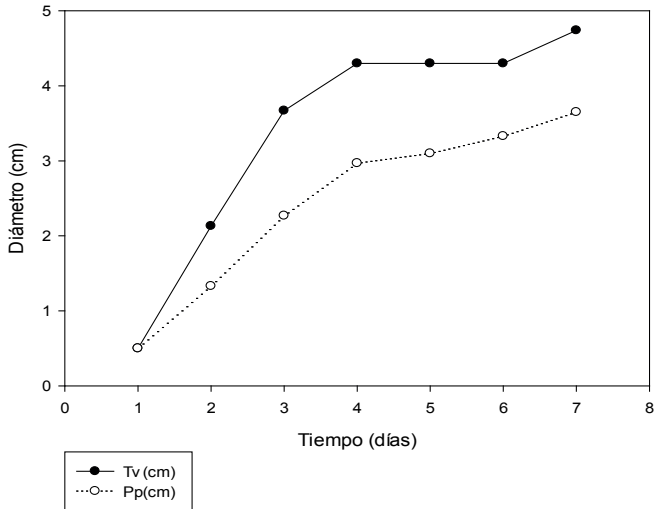

D.

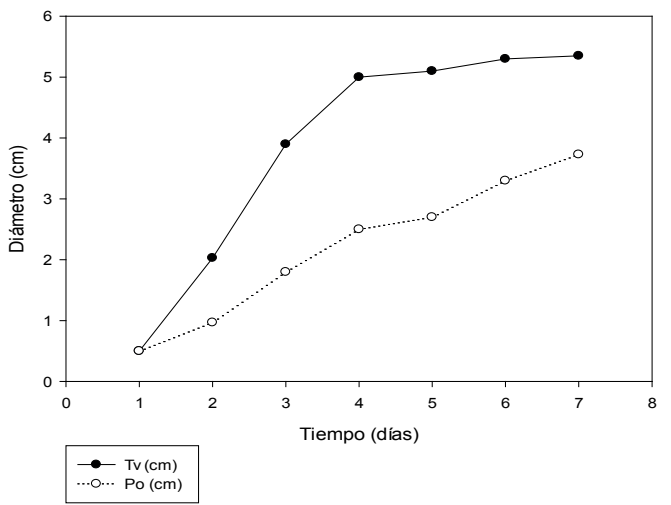

E.

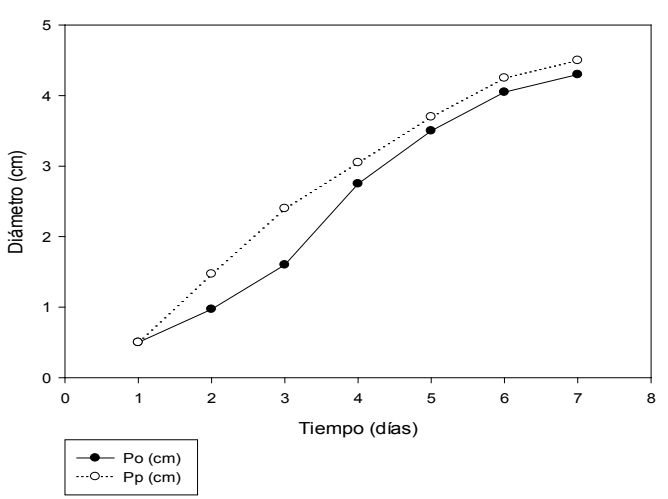

F.

Figura 3. Crecimiento para los tres tratamientos en AST bajo interacción: A,B,C. Crecimiento para los tres tratamientos en PDA bajo interacción: D,E,F.

\section{Agradecimientos}

Los autores expresan agradecimientos a la Universidad Nacional de Colombia, sede Medellín por el apoyo a través de la infraestructura del Laboratorio de Química Experimental. Financiación: Esta investigación fue financiada por la Convocatoria Jóvenes Investigadores e Innovadores 617, Año 2013 de Colciencias y la Universidad Nacional de Colombia, sede Medellín, Proyecto Código 201010013080.

\section{Referencias}

[1] J. A. Fernández, L. M. Henao, A. M. Pedroza Rodríguez, and B. Quevedo Hidalgo, "Inmovilización de hongos ligninolíticos para la remoción del colorante negro reactivo 5", Rev. Col. de Biotecn., vol. 11, no. 1, pp. 59-72, 2009.

[2] S. Gouma, S. Fragoeiro, A. C. Bastos, and N. Magan, "Bacterial and Fungal Bioremediation Strategies" in Microbial Biodegradation and 
Bioremediation, D. Surajit, Ed. Elsevier, 2014, pp. 301-323.

[3] E. Marco-Urrea, and C. A. Reddy, "Degradation of Chloro-organic Pollutants by White Rot Fungi" in Microbial Degradation of Xenobiotics, S. N. Singh, Ed. Berlin Heidelberg: Springer-Verlag, 2012. pp. 31-66

[4] M. C. Diez, "Biological aspects involved in the degradation of organic pollutants", J. Soil Sci. Plant Nutr., vol. 10, no. 3, pp. 244-267, 2010.

[5] X. Yang, J. Wang, X. Zhao, Q. Wang, and R. Xue, "Increasing manganese peroxidase production and biodecolorization of triphenylmethane dyes by novel fungal consortium", Biores. Techn., vol. 102, no. 22, pp. 10535-10541, 2011.

[6] R-G. Saratale, G-D. Saratale, D-C. Kalyani, JS. Chang, and S-P. Govindwar, "Enhanced decolorization and biodegradation of textile azo dye Scarlet $\mathrm{R}$ by using developed microbial consortium", Biores. Techn., vol. 100, no. 9, pp. 2493-2500, 2009.

[7] P. Malaviya, and V. S. Rathore, "Bioremediation of pulp and paper mill effluent by a novel fungal consortium isolated from polluted soil", Biores. Techn., vol. 98, no. 18, pp. 3647-3651, 2007.

[8] P. J. Bottomley, " Microbial Ecology" in Principles and Applications of Soil Microbiology, D. M. Sylvia, J. J. Fuhrman, H P. Gartel, D. A. Zuberer, Ed. Prentice Hall 2 Edition, 2004, pp. 149-167.

[9] D K. Sharma, H. S. Saini, M. Singh, S. S. Chimni, and B. S. Chadha, "Isolation and characterization of microorganisms capable of decolorizing various triphenylmethane dyes", J. Basic. Microbiol., vol. 44, pp. 59-65, 2004.

[10] A. Hernández-Mansilla, and C. Rosón-Álvarez, "Evaluación preliminar del crecimiento y la esporulación de Aschersonia aleyrodis Webber en medios de cultivo convencionales", Fitosan, vol. 9, no. 3, pp. 61-63, 2005.

[11] P. Kaushik, and A. Malik, "Fungal dye decolourization: Recent advances and future potential", Environment International, vol. 35, no. 1, pp. 127-141, 2009.
[12] R. D. Koyani, G. V. Sanghvi, R. K Sharma, and K. S. Rajput "Contribution of lignin degrading enzymes in decolourisation and degradation of reactive textile dyes", Int. Biodeterior. Biodegrad., vol. 77, pp. 1-9, 2013.

[13] J. H. Andrews, "Relevance of r-and K-theory to the ecology of plants pathogens", In: Klug Reddy, C. A. (eds.), Current perspectives in microbial ecology. American society of Microbiology, Washington, DC. pp. 1-7, 1984.

[14] A. H. Molla, A. Fakhru, S. Abd-Azizand, and M. M. Hanafi, "In-vitro compatibility evaluation of fungal mixed culture for bioconversion of domestic wastewater sludge", World J. Microbiol Biotechn., vol. 17, pp. 849-856, 2001.

[15] S. Albert, D. Chauhan, B. Pandya, and A. Padhiar, "Screening of Trichoderma sp. As potential fungal partner in co-culturing with white rot fungi for efficient bio-pulping", Global J. Biotechn. E Biochem., vol. 6, no. 3, pp. 95-101, 2011.

[16] H. Kausar, M. Sariah, H. Mohd Saud, M. Zahangir Alam, and M. Razi Ismail, "Development of compatible lignocellulolytic fungal consortium for rapid composting of rice straw", Int. Biodet. Biodegr., vol. 64 , no. 7, pp. 594600, 2010.

[17] R. Rajendran, S-K. Sundaram, B-V. Sridevi, P. Prabhavath, and V. Gopi, "Biodetoxification of azo dye containing textile effluent through adapted fungal strains", J. Environm. Sci. Techn., vol. 5, no. 1, pp. 29-41, 2012.

[18] M. M. Martínez, and A. M. Pedroza, Manual de Microbiología Ambiental. Pontificia Universidad Javeriana, Centro Editorial Javeriano (CEJA), p. 58, 2007.

[19] S. Benítez, J. Bentley, P. Bustamante, L-C. Sánchez, and L. Corrales, "Aislamiento de los microorganismos cultivables de la rizosfera de Ornithogalum umbellatum y evaluación del posible efecto biocontrolador en dos patógenos del suelo", NOVA, vol. 5, pp. 147-153, 2007.

[20] K. Brijwani, H, S. Oberoi, and P-V. Vadlani, "Production of a cellulolytic enzyme system in mixed-culture solid-state fermentation of soybean hulls supplemented with wheat bran", Process Biochem., vol. 45, no.1, pp. 120-128, 2010. 
[21] L. Qian, and B. Chen, "Enhanced oxidation of benzo[a]pyrene by crude enzyme extracts produced during interspecific fungal interaction of Trametes versicolor and Phanerochaete chrysosporium", J. Environ. Sci., vol. 24, pp. 1639-1646, 2012.
[22] M. Carabajal., L. Levin., E. Albertó, and B. Lechner, "Effect of co-cultivation of two Pleurotus species on lignocellulolytic enzyme production and mushroom fructification", Int. Biodeterior. Biodegrad., vol. 66, 71-76, 2012. 